Recibido: 24 julio 2012

Aprobado: 3 septiembre 2012
Perspectiva del dispensario, 1933. Fuente: Archivo Administrativo de Barcelona, imagen suministrada por el autor

\section{LA RESTAURACIÓN DE LA MODERNIDAD: EL DISPENSARIO ANTITUBERCULOSO DE BARCELONA*}

Luca Bullaro **

Universidad Nacional de Colombia sede Medellín (Colombia)

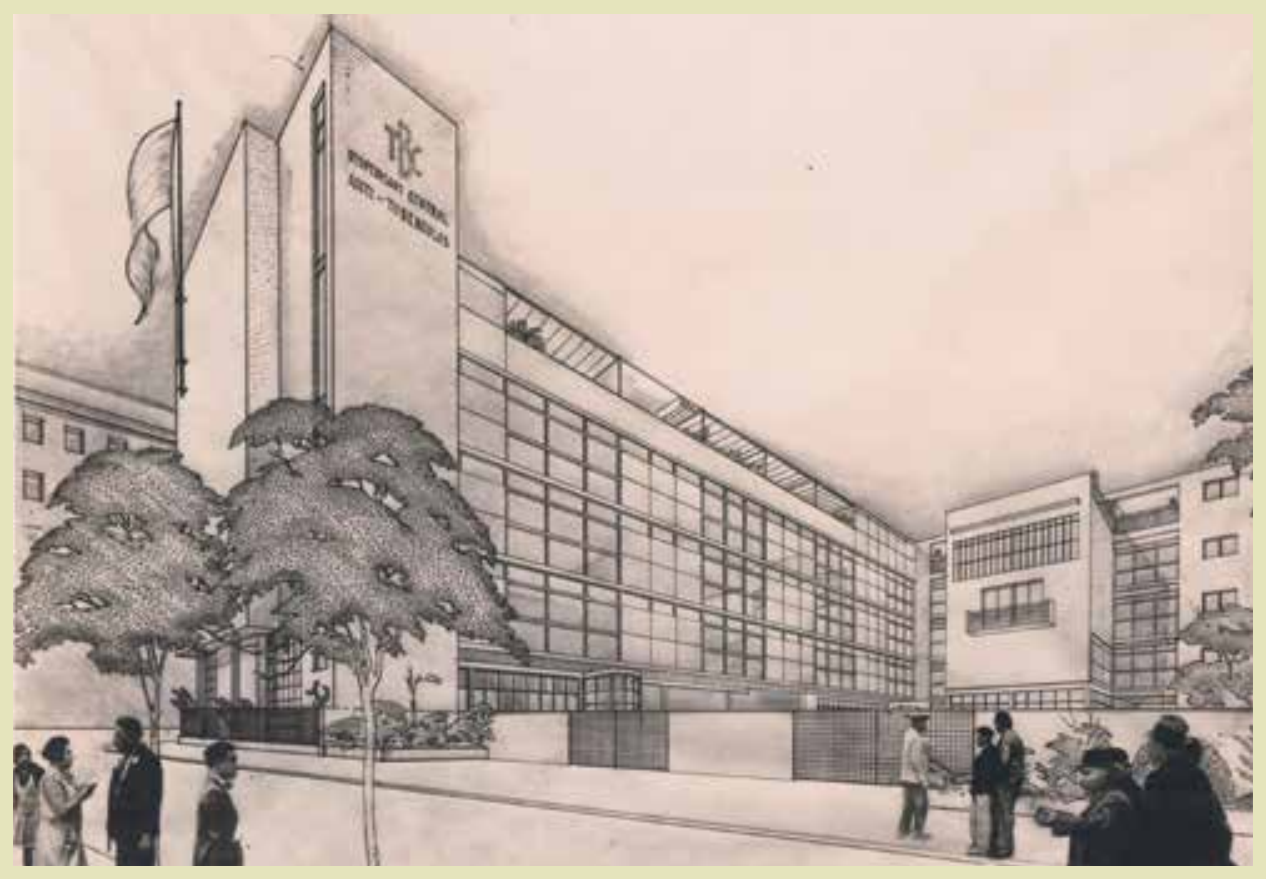

\section{RESUMEN}

El texto expone los resultados de la investigación que se originó en el ámbito del Doctorado "Il restauro del Moderno" organizado por el "Dipartimento di Storia e Progetto nell'Architettura di Palermo y se desarrolló a partir de febrero del 2010 en la sede de Medellín de la Universidad Nacional de Colombia. Se analiza la obra de los arquitectos catalanes Josep Lluís Sert y Josep Torres Clavé, fundadores del GATCPAC, realizada en los años treinta del siglo XX, y en particular, El Pabellón de la República española, La Casa Bloc y el Dispensario antituberculoso de Barcelona. De este último la investigación propone el proyecto de restauración, reutilización y ampliación e indaga la posibilidad de conexión con los espacios públicos urbanos adyacentes para dar vida a un conjunto de lugares públicos conectados que tengan un desarrollo democrático también en los niveles superiores con la creación, en la terraza-jardín del edificio, de un sistema público de mirador urbano.

\section{PALABRAS CLAVE}

Movimiento Moderno, Josep Lluis Sert, Gatcpac, Barcelona, Restauración, Ampliación 


\section{THE MODERN HERITAGE RESTORATION: THE BARCELONA CENTRAL DISPENSARY}

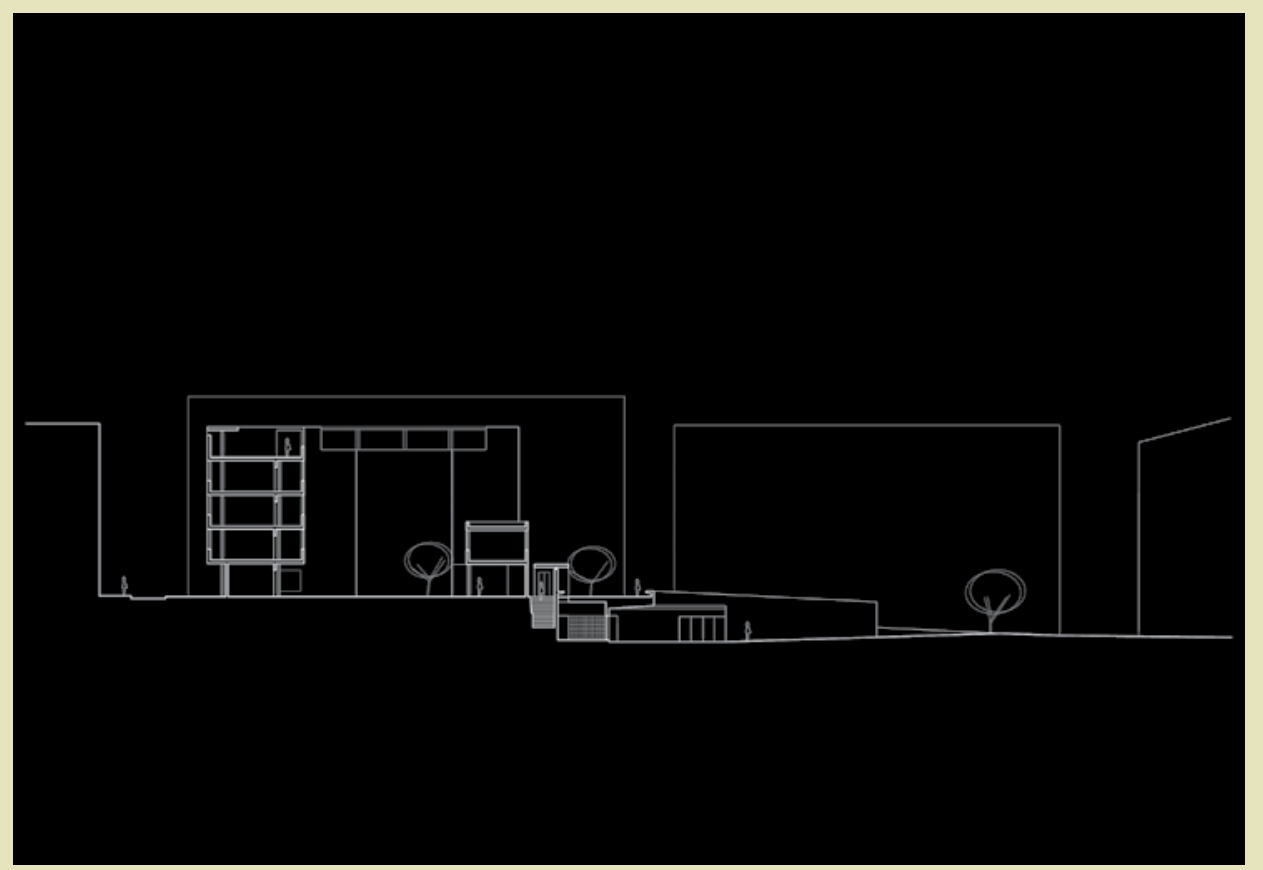

\section{ABSTRACT}

The text displays the result of the research that was originated in the context of the PhD. research "II Restauro del Moderno" structured by the Dipartimento di Storia e Progetto nell'Architettura di Palermo, and was developed since February 2010 at the Universidad Nacional de Colombia in Medellín.

It analyzes the firsts works of Catalans architects Josep Lluís Sert and Josep Torres Clavé, founders of GATCPAC, and in particularly one of the first modern spanish constructions, built in Barcelona in the 1930's, the "Dispensario antituberculoso". The research suggests the work of restoration, reuse and expansion of the Dispensario, highlighting the possibility of connection with the contiguous public spaces, with the intent of producing a system of jointed community places; these would have a democratic development, also at the higher levels, with the design, in the terrace-garden, of an urban balcony.

\section{KEY WORDS}

Modern Movement, Josep Lluis Sert, Gatcpac, Barcelona, Restoration, Expansion. 


\section{INTRODUCCIÓN}

Junto con la Casa Bloc, el Dispensario antituberculoso representa un manifiesto urbanístico y arquitectónico del Moderno en Cataluña que sienta las bases del "Plan Maciá", el plan de transformación y ampliación de Barcelona desarrollado conjuntamente por Sert, Le Corbusier y los miembros del GATCPAC'. En 1934, el Departamento de Sanidad y Asistencia Social de la Generalitat Republicana encargó a Josep LI. Sert, J. Torres Clavé y J. B. Subirana el proyecto del Dispensario antituberculoso dentro de su política de socialización hospitalaria y lucha contra la tuberculosis. El edificio se emplaza en el Raval, un barrio extremadamente denso de Barcelona que el nuevo plan pretendía higienizar liberando los interiores de manzana más densificados y degradados. La planta del edificio está concebida en forma de "L", respeta las alineaciones de las dos calles adyacentes y se abre hacia al interior de la manzana con la creación de un patio verde que proporciona el acceso a los espacios interiores y concilia la morfología compacta de la ciudad tradicional con los nuevos principios del Movimiento Moderno.

La estructura metálica se diferencia visiblemente de los cerramientos, en los cuales se mezclan con gran sensibilidad y respeto hacia al contexto urbano materiales modernos y antiguos: elementos semitransparentes de pavés, láminas de fibrocemento, grandes paneles cuadrados prefabricados de tonalidad rosada, vidrio de diferentes tipologías, cerámica esmaltada.

Acabado durante la Guerra Civil, constituye una de las obras más representativas del movimiento racionalista catalán, paradigma de los principios arquitectónicos debatidos en los CIAM, de los cuales Sert fue mediador y director durante algunos años. La investigación propone el proyecto de restauro, reutilización y ampliación del Dispensario Antituberculoso de Barcelona, indaga la posibilidad de conexión con los espacios públicos urbanos adyacentes, entre la Plaza Universidad y los nuevos edificios del sistema de equipamientos culturales y expositivos del barrio Raval, para dar vida a un conjunto de espacios públicos en conexión que tengan un desarrollo inédito del espacio democrático en los niveles inferiores - con la propuesta de patios excavados - y superiores con la creación, en la terraza-jardín del edificio, de un sistema público de mirador urbano.

\section{EL MOVIMIENTO MODERNO EN BARCELONA Y LA INFLUENCIA DE LE CORBUSIER}

En la Escuela de Arquitectura de Barcelona, a partir de la mitad de los años veinte, los estudiantes más inquietos, entre los cuales Josep Luis Sert y Josep Torres Clavé, intuyen que sus ideas vanguardistas van en una dirección diferente con respecto a los intereses del ambiente académico catalán, donde los docentes - exponentes de las corrientes clasicistas o eclécticas - no estaban dispuestos a acoger el Espíritu nuevo anunciado por los jóvenes maestros de la modernidad, e inician una búsqueda personal, y por caminos inéditos, con el fin de acercarse a la comprensión de los principios de las más recientes tendencias de la arquitectura. ${ }^{2}$

En 1926, se funda la Asociación de alumnos de la Escuela Superior de Arquitectura de Barcelona, que tiene como presidente a Josep Torres Clavé y es considerada como el embrión del

Grup d'Arquitectes i Técnics Catalans per al Progrés de l'Arquitectura Contemporánia.

2 En la conferencia organizada por la Asociación de Alumnos de la Escuela de Arquitectura de Barcelona, y publicada en la revista A.C., Sert afirma que como jóvenes tenían la obligación de seguir la tendencia moderna, pero asimilándola y adaptándola al espíritu de la Cataluña y a la tradiciones mediterráneas que no se podían jamás renegar. Los arquitectos barceloneses tenían que crear "una arquitectura viva, palpitante y joven, creación constante". Conferencia de Josep Lluis Sert, publicada en la revista "A.C." No. 16, IV trimestre 1934, pp. 43-44 
grupo GATPAC. Es esta la primera expresión de la voluntad de definir algunas directrices que guíen la intensa actividad profesional, concentrada entre los años veinte y treinta de los jóvenes arquitectos catalanes.

En 1925 en París se inaugura la "Exposición Internacional des arts décoratifs et industriels modernes", himno a la técnica moderna y al progreso. El catalán Rafael Benet ${ }^{3}$ es enviado a cubrir el evento para el periódico de Barcelona "La Veu de Catalunya" y dedica un amplio espacio - con el título "Cròniques d'art de Paris" - a la descripción crítica del Pabellón de "L'Esprit Nouveau" de Le Corbusier y Pierre Jeanneret, ilustra los alojamientos-tipo de realización industrial que utilizan sistemáticamente elementos prefabricados y el estudio de los principios de estandarización en las agrupaciones urbanas.

Benet sostiene como ineludible la lectura del manifiesto de Le Corbusier "Vers une architecture nouvelle" y no se cansa de celebrar un nuevo tipo de construcción que se basa en las proporciones armónicas, que alaga el "renovado clasicismo" del joven arquitecto suizo. ${ }^{4}$

Según el historiador español Josep Rovira la lectura de este texto pone en contacto al joven Josep Lluis Sert con el universo teórico de aquel intelectual que poco tiempo después sería su maestro. Ya anciano, Sert recordaba - durante una de las conversaciones veraniegas en Ibiza - que en París en 1926 había comprado tres libros de Le Corbusier, los había leído con pasión y discutido, a su regreso en Barcelona, con sus compañeros catalanes.

En Mayo de 1928 Le Corbusier viaja a Madrid invitado por el arquitecto García Mercandal, apasionado conocedor de las nuevas tendencias europeas, a dar una conferencia en la Residencia de Estudiantes $^{6}$ y - como él mismo recuerda - recibe un telegrama firmado por Sert que lo cita en la estación de Barcelona, a las diez de la noche del 15 de Mayo, donde lo recibirían algunos jóvenes llenos de energía.

3 Rafael Benet, pintor y crítico, desde 1925 director de la revista La ciutat i la Casa, periódico de la Asociación de los arquitectos de Cataluña, instaura relaciones constantes con las importantes revistas de arquitectura extranjeras, como Moderne Bauformen, Architectural Review y L'architecture vivant. Benet vive en París entre julio y octubre y publica una serie de artículos monográficos sobre las manifestaciones más notables de la exposición. Defensor de un clasicismo "actualizado", a su vuelta a Barcelona irá también polemizando contra las tendencias del pasado que predominan todavía en el mundo artístico catalán. Véase el texto: ROVIRA, José María, José Lluis Sert 190I-1983, Electa, Milano 2000, pp. I4-16.

4 Las referencias a los artículos de Rafael Benet se encuentran también en el texto de Antonio Pizza, Edificio de apartamentos, contenido en Rovira, José María, Sert 1928-1979, Medio siglo de arquitectura, Obra completa, Fundació Miró ed., Barcelona 2005, pp. 20-21.

5 En los alrededores de Madrid Le Corbusier visita, acompañado por Mercadal, Segovia, Toledo y el palacio del Escorial. Llena los carnés de dibujos y apuntes que fijan las imágenes de un paisaje áspero y austero: iglesias fortificadas, castillos, casas a racimos sobre las pendientes. "Las casas en tierras españolas - escribe LC - son castas. Ninguna suciedad, ninguna perversión del dinero. Este país es puro y noble”. Los esbozos originales del carné están reproducidos en las páginas del volumen: Lahuerta, Juan José, Le Corbusier e la Spagna, Electa, Milano $200 \mathrm{I}$.

6 En la Residencia de Estudiantes de Madrid se dieron también conferencias de los maestros Gropius, Mendelsohn, Van Doesburg. Fernando García Mercadal, a través de las páginas de la revista "Arquitectura", combatió para introducir la nueva arquitectura en España, participó en la reunión de los CIAM en junio de 1928 y fue nombrado delegado español en los congresos siguientes. Para profundizar sobre la obra y en la biografía de García Mercadal se remite al número monográfico de la revista de crítica arquitectónica «DC» No. 9, de octubre 2003, editado por el Departamento de crítica arquitectónica de la $E T S A B$, en la Facultad de Arquitectura de la Universidad Politécnica de Cataluña.

Ignasi de Solá-Morales compara la situación arquitectónica madrileña con la de Barcelona, identificada una con la figura de Mercadal y otra con Sert, y acentúa la grande influencia que el maestro suizo ejerce sobre el grupo catalán: “(...) De un lado Fernando García Mercadal, brillante proyectista, viajero curioso por Centroeuropa e incisivo conocedor de muchos de los arquitectos y obras de la nueva arquitectura. Del otro lado, Josep Lluís Sert, minucioso y elegante diseñador, cosmopolita de nacimiento y futuro activista en la escena de la cultura arquitectónica europea a la sombra de su maestro Le Corbusier. El marco de interés madrileño con relación a la nueva arquitectura, como bien muestran otras revistas, era prioritariamente germanófilo y en algún caso italiano. El marco catalán sería, en buena parte, de estricta observancia lecorbusierana. Hay una serie de temas comunes para los cuales se desarrolla un discurso común. La crítica a las escuelas de arquitectura y el modo académico de enseñar: formalista, historicista, retórico. (...) La visión urbana de la arquitectura y la conexión entre las entonces separadas disciplinas de la arquitectura y el urbanismo reciben una común atención." de Solá-Morales, Ignaci, Estrabismo barcelonés, en la revista "Residencia" No. 8, junio 1999, pp. 17-18. 
Le Corbusier presenta dos conferencias: la primera, titulada "Arquitectura, mobiliario, obra de arte", en la cual ilustra el recorrido que conduce a la nueva manera de hacer arquitectura, y los cinco puntos que había enunciado, con su socio Pierre Jeanneret el año anterior. Habla también de la belleza de las formas puras y de las ventajas de los nuevos materiales como el acero, el hormigón armado y el muro-cortina de vidrio.

La segunda conferencia era titulada "Una casa, un palacio". La residencia era presentada como una "máquina para habitar" y también como un "lugar para satisfacer necesidades superiores". El maestro evocó el Partenón como modelo eterno de lógica y racionalidad. En la parte final de la conferencia el arquitecto suizo mostró a los estudiantes algunas imágenes del proyecto de concurso para la nueva Sede de la Sociedad de las Naciones de Ginebra.

Por aquellos jóvenes apasionados las ideas de Le Corbusier representaron sin duda una inyección de vitalidad en comparación a las estrategias urbanas aristócratas de una ciudad que no se ocupaba de los grandes problemas sociales.

\section{Primeros experimentos del Movimiento Moderno Catalán}

De los edificios del movimiento moderno realizados en Barcelona en los años treinta, el Dispensario antituberculoso y el complejo residencial Casa Bloc, ambos proyectados por Sert, Clavé y Subirana, presentan un aspecto inédito: han sido pensados como edificios semipúblicos caracterizados por un sistema innovador y complejo de recorridos urbanos a nivel de planta baja.

Un tercer proyecto, el Pabellón de la República española, donde Sert desarrolla el mismo tema en un contexto diferente, es una arquitectura experimental al interior del grande espacio expositivo de París que después de muchos años se reconstruye en la zona deportiva de Montabau en Barcelona.

Las tres arquitecturas acogen en su interior sistemas espaciales urbanos de características diferentes:

I. Dos grandes plazas jardín intercomunicadas en la Casa Bloc.

2. Un patio conformado mediante la articulación de dos volúmenes dispuestos en forma de "L" en el Dispensario antituberculoso.

3. Un patio con una cubierta móvil contiguo al "museo al aire libre" en el Pabellón de la República española.

Espacios públicos abiertos en relación directa con el interior, privado en los pisos altos y semipúblico en la planta baja; espacios que reinterpretan, a partir de la relación entre arquitectura y sistema urbano y de la correspondencia interior-exterior, algunas características típicas de la arquitectura de los países mediterráneos.

\section{El Pabellón de la República española en la Exposición Internacional de París de 1937}

En el pabellón el tema príncipe del recorrido peatonal público forma un doble sistema: el primero a nivel de la planta baja y el segundo suspendido, se trenzan los espacios internos de exposición y los externos, algunos descubiertos y otros cubiertos para proteger los lugares de la lluvia, del sol y de la humedad de la noche parisina. 
La planta baja es libre: una plaza cubierta marca el ingreso al pabellón con un pórtico rojo salpicado por las obras de arte símbolos de democracia y de esperanza: el famoso lienzo de Picasso $^{7}$ acoge al visitante acompañado de una hilera de pilares en acero. La pavimentación es homogénea de manera que en la planta baja hay una continuidad ininterrumpida entre el interior y el exterior; continuidad física y visual entre la ciudad, la zona porticada, el patio y el escenario donde se concluye el recorrido peatonal. El suelo del patio está sutilmente inclinado generando una pequeña plaza cuadrada que baja hacia la zona para conciertos, conferencias y espectáculos teatrales al aire libre. ${ }^{8}$

Desde el patio una rampa curvilínea conduce al piso superior donde una escalera permite la conexión con el último nivel. Una promenade inédita de corte corbuseriano, interesante por el cambio repentino de altura en el punto de vista del observador, la rotación del mismo y el desdoblamiento del sistema de ascenso escalera-rampa.

En el primer piso inicia el recorrido expositivo cubierto, más privado y sereno: se desarrolla siguiendo el perímetro del rectángulo alargado de la planta, se interrumpe en la mitad con la posibilidad de asomarse hacia al nivel inferior en correspondencia al espacio a doble altura; continua y concluye reencontrándose con la escalera exterior que permite una nueva conexión con el espacio de la cota 0 , la cota de la urbe.

El recorrido circular se cierra. La escalera, inclinada respecto al eje del volumen principal señala con el descenso a la planta baja el final de la experiencia arquitectónica, artística, cultural y política. ${ }^{9}$

Con respecto a la estructura y los materiales utilizados, Sert ejecuta una arquitectura simple y económica, rápida de construir y desmontar, según algunos de los principios básicos del movimiento moderno. ${ }^{10}$

La cubierta del patio representa una idea innovadora en el ámbito de la arquitectura de los años treinta y al mismo tiempo rememora la tradición de las coberturas ligeras de los patios de Andalucía: un sistema que Sert ya había incorporado en sus proyectos barceloneses donde en las terrazas aparecen siempre blancos toldos "bioclimáticos" del mismo tipo. Una estructura de cables en acero soporta un sistema de telas que corren electrónicamente sobre sí mismos de modo que el patio se pueda transformar en un lugar abrigado y adecuado para las representaciones teatrales y los programas de conciertos.

\section{La Casa Bloc. Barcelona, 1932}

La Casa Bloc es uno de los proyectos de mayor envergadura realizado al principio de los años treinta por José Luis Sert y Torres Clavé, con la colaboración técnica de Joan Baptista Subirana y de algunos de los jóvenes arquitectos miembros del GATCPAC."

7 "(...) Una etapa de activismo político y cultural que habría de culminar en el dramático Pabellón de España en la Exposición Internacional de París de 1937, un grito de auxilio de la República en guerra que expuso el Guernica de Picasso, junto a la Fuente de mercurio de Calder, La Monserrat de Julio González, El segador de Miró, o el gran tótem de Alberto El pueblo español tiene un camino que conduce a una estrella". Fernández-Galiano, Luis, Sert o no Sert: el maestro menguante, publicado en las páginas del suplemento "Babelia" de "El País", 30 de junio de 200I, p. 21.

8 Para la descripción de las relaciones entre arte y arquitectura al interior del Pabellón, véase: Freixa, Jaime, Josep Lluis Sert, Obras y Proyectos, GG, Barcelona 1979, pp. 46-5I.

9 Véase el volumen a cargo de K. Bastlund y el texto de prólogo de Giedion, Sigfried: J. L. Sert: Architecture, city planning, urban design, Les Edicion d' Architecture, Zurich 1967, pp.7-8.

10 J.L. Sert, Apuntes autobiogràficos, in Freixa, Jaime, Josep Lluis Sert, Santa\&Cole Barcelona 2005. pp. 230-237.

II Tarragó, S., Reivindicación de la casa Bloc, en la revista "Cuadernos de arquitectura y urbanismo" n. 40, 1980, pp. 41-43. Véase también el texto Casa Bloc, a cargo de la redacción de la revista "2C Construcción de la ciudad", No. I5-16, mayo 1980, p. 41 . 
Una obra que difunde la poética de Le Corbusier en Cataluña y la traduce según las exigencias urbanas, culturales y figurativas de Barcelona. ${ }^{12}$

El espacio público exterior asume una importancia relevante en el desarrollo del proyecto y asienta como un elemento fundacional al interior del complejo de habitaciones. Un microcosmos urbano que logra dialogar con la morfología de la ciudad. A diferencia del patio del Dispensario, los patios aquí se expanden, se duplican y adquieren una dimensión metropolitana: dos grandes plazas jardín conectadas entre ellas animan la vida social, artesanal y comercial del complejo arquitectónico.

Los aspectos que ligan la Casa Bloc al Dispensario - ambos proyectos realizados a principios de los años treinta - son la relación fuerte con el lenguaje y los principios de Le Corbusier, el empleo de las nuevas tecnologías constructivas y la relevancia que se le da al sistema de espacio público dentro del perímetro de la nueva arquitectura y que tiende a conformar un continuum con la ciudad.

La Casa Bloc, como el Dispensario, se alinea con la calle principal, la avenida Torras i Bages, descomponiéndose en dos partes: la primera, abierta, deja la vista correr hacia al grande patio; la segunda, construida, se abre igualmente a la ciudad a través de un porche que ocupa todo el largo del lote frente a la calle y que - como en el Pabellón de la República conecta el espacio de la ciudad con el corazón democrático interior.

Otro volumen suspendido sobre pilares divide el gran espacio público central en dos lugares más pequeños en relación directa entre ellos y sin crear algún tipo de ruptura en el recorrido público a nivel de planta baja. El sistema habitacional está conformado por un bloque de 207 apartamentos duplex con una fachada de 170 metros sobre la avenida Torres i Bages.

En la planta baja están dispuestos los servicios comunitarios necesarios para la vivienda obrera: una biblioteca pública, piscina para adultos y niños, una guardería, bar, locales comerciales, lavandería y baños públicos. ${ }^{13}$

Los núcleos de circulación vertical, escaleras y ascensores, se encuentran en las esquinas de manera que se refuerce a nivel figurativo la importancia del volumen puro, y permite también que cada vivienda goce de vista a ambos lados y de aireación directa y ventilación cruzada en todas las dependencias. ${ }^{14}$

La adopción de un sistema estructural de esqueleto está en línea con las cuestiones conceptuales propias del Movimiento Moderno promovidas por Le Corbusier. La estructura principal así concebida permite la máxima libertad en la planta baja para la instalación de los varios tipos de servicios colectivos. La Casa Bloc que desarrolla las enseñanzas corbuserianas es portadora de mensajes modernos y eficaces ${ }^{15}$ : planta a redent, gallería, pilotis, terraza habitable, apartamentos de dos plantas, es el prototipo de la "nueva unidad de habitación" de la ciudad funcional.

12 Zevi, Bruno, Sert's architecture in the Miró Foundation, Ed. Polígrafa, Barcelona 1976, p. 34.

13 Véase el texto de Carlos Martí Arís, La casa Bloc, un fragmento de ciudad moderna, en la revista "A\&V Arquitectura y vivienda" No. II, 1987, pp. 20-23.

Sert publica el proyecto en el volumen Can our cities survive? concentrando la atención en la relación entre espacio público y privado, abierto y cerrado y en los servicios que se tenían que realizar en los espacios de la planta baja. Sert, Josep Lluis, Can our cities survive? And ABC of urban problems, their analysis, their solutions. Harvard University Press, Cambridge, 1942, pp. 72-74. (ed. en catalán, Poden sobreviure les nostres ciutats?, Generalitat de Catalunya ed., Barcelona 1983).

I4 El proyecto de la Casa Bloc fue publicado, acompañado por la memoria original, en el número I I de la revista «A.C.», tercer trimestre de 1933, pp. 22-26

15 Rovira, José Maria, José Luis Sert 1902-1983, Electa, Milano 2000, p. 72. 
Para los miembros del GATCPAC era un proyecto ejemplar: Sert en las páginas de la revista $A C$ escribe que se trataba de un prototipo para el desarrollo de una operación a gran escala, el primer paso para el proyecto urbano que anhelaba transformar el plan Cerdá.

La malla de la futura Barcelona se debía abrir, como se abre en el proyecto de la Casa Bloc, en busca del aire y de la luz, sirviéndose de una implantación en forma de " $S$ ", evocando las raíces figurativas de la civilización mediterránea. ${ }^{16}$

\section{EL DISPENSARIO ANTITUBERCULOSO. Barcelona, 1933}

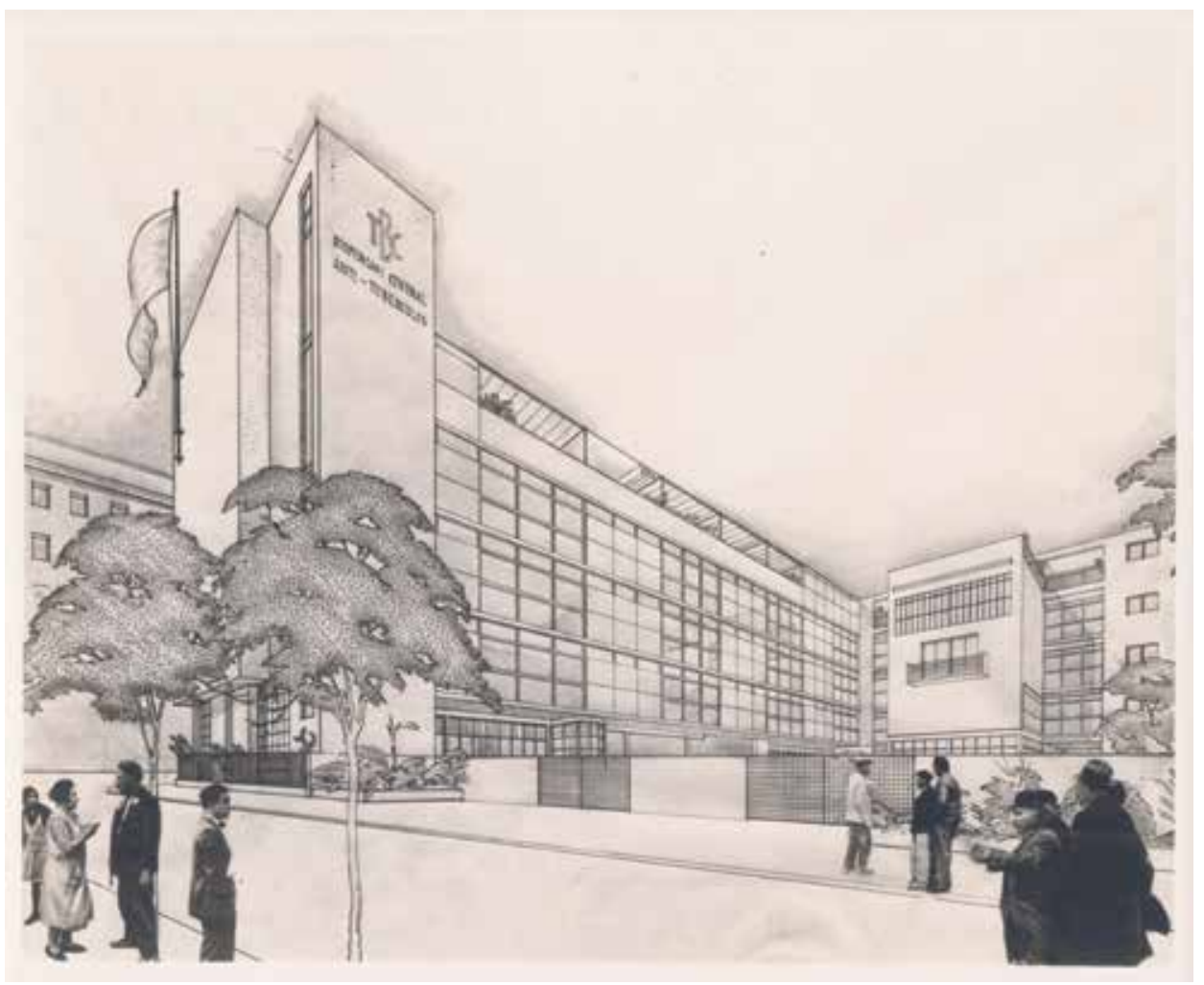

El Dispensario antituberculoso está ubicado en el antiguo barrio del Raval. El programa de uso múltiple se organiza en dos volúmenes perpendiculares que forman en planta una "L" que se repite en los cuatro niveles dispuestos según la orientación más favorable para aprovechar el contorno irregular del lote y una buena exposición.

El complejo delimita un espacio central libre que se configura también como patio de acceso ${ }^{17}$ y se completa con un pequeño pabellón elevado sobre pilotis que actúa como casa
Figura I. Perspectiva del dispensario, 1933. Fuente: Archivo administrativo de Barcelona, suministrada por el autor

6 Completada la construcción, al final de la guerra civil la Casa Bloc fue confiscada a la Generalitat de Catalunya. En I94I en el ala sur del edificio se creó la residencia de las viudas y de los huérfanos del ejército. En la actualidad está en curso de realización un importante proyecto de restauración, empezado gracias a los estudios de Raimon Torres, que rehabilitará el conjunto arquitectónico respetando la configuración originaria. García, Carolina Beatriz, Casa Bloc, en Rovira, José María, Sert 1928-1979. Medio siglo de arquitectura. Obra completa, Actar, Barcelona 2005, p. 47.

17 El patio es un elemento presente en la poética de Sert desde su primera formación como arquitecto. Fascinado por las casas del vernáculo de lbiza, entusiasta visitante, junto a Miró, de los pueblos andaluces, admirador de los pueblos blancos de las islas del Egeo, Sert rescató el tema milenario del patio en el Pabellón de la República española de 1937 en París, luego en las pequeñas casas de la unidad vecinal del plan piloto de Chimbote en Perú de 1946, y en gran escala en la Embajada de los Estados Unidos en Bagdad de 1955, y en su misma casa en Cambridge desarrollada alrededor de tres patios. J.LI. Sert, Changing Views in the Urban Environment, 1963, traducido al español y publicado por Freixa, Jaume, J.LI.Sert, Santa \& Cole, Barcelona 2005, pp. 219-220. 
para el guardia. Se crea así un patio cerrado y abierto al mismo tiempo, sugerido por bordes virtuales más que por muros construidos. ${ }^{18}$

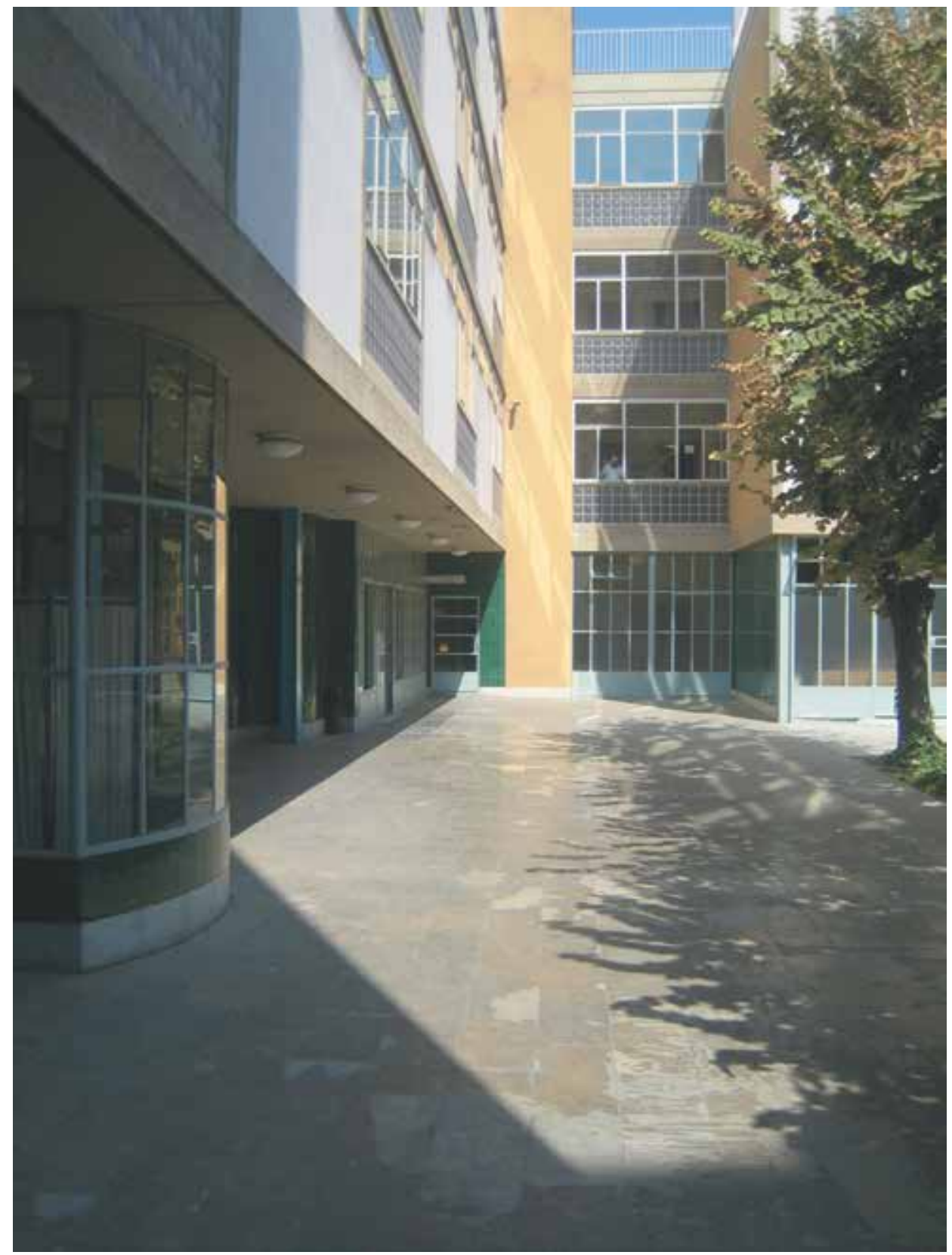

La distribución interna del espacio está organizada para obtener el mejor soleamiento posible con un intercambio de aire constante gracias al sistema de ventilación cruzada; los ambientes están servidos por un corredor a lo largo del muro exterior que se asoma hacia al patio con ventanas altas que permiten el intercambio de aire y evita corrientes fastidiosas.

El edificio se alinea sobre la vía principal respeta las dimensiones de la calle corredor y la altura de los edificios vecinos. La configuración del ángulo entre el carrer Torres i Amat y Sant Bernat se adapta a la estructura vial de la ciudad, rechaza en planta los noventa grados

18 A. Pizza, Dispensario antituberculoso de Barcelona, 1933 1937. COAA, Almería 1993, p. 17. Se remite también a las descripciones críticas del edificio escritas por O. Bohigas, J. Freixa, J. M. Rovira y a las de Carlos Martí Arís, y Xavier Monteys publicadas en la revista "2C, Construcción de la ciudad", n. 15-16, Barcelona 1980, pp. 62-67 
y forma un ángulo agudo que respeta la malla urbana del barrio. Del lado opuesto el edificio se abre al aire y al sol con una plaza verde sobre la cual se asoman los espacios de la planta baja, los corredores y las salas de espera de los niveles superiores.

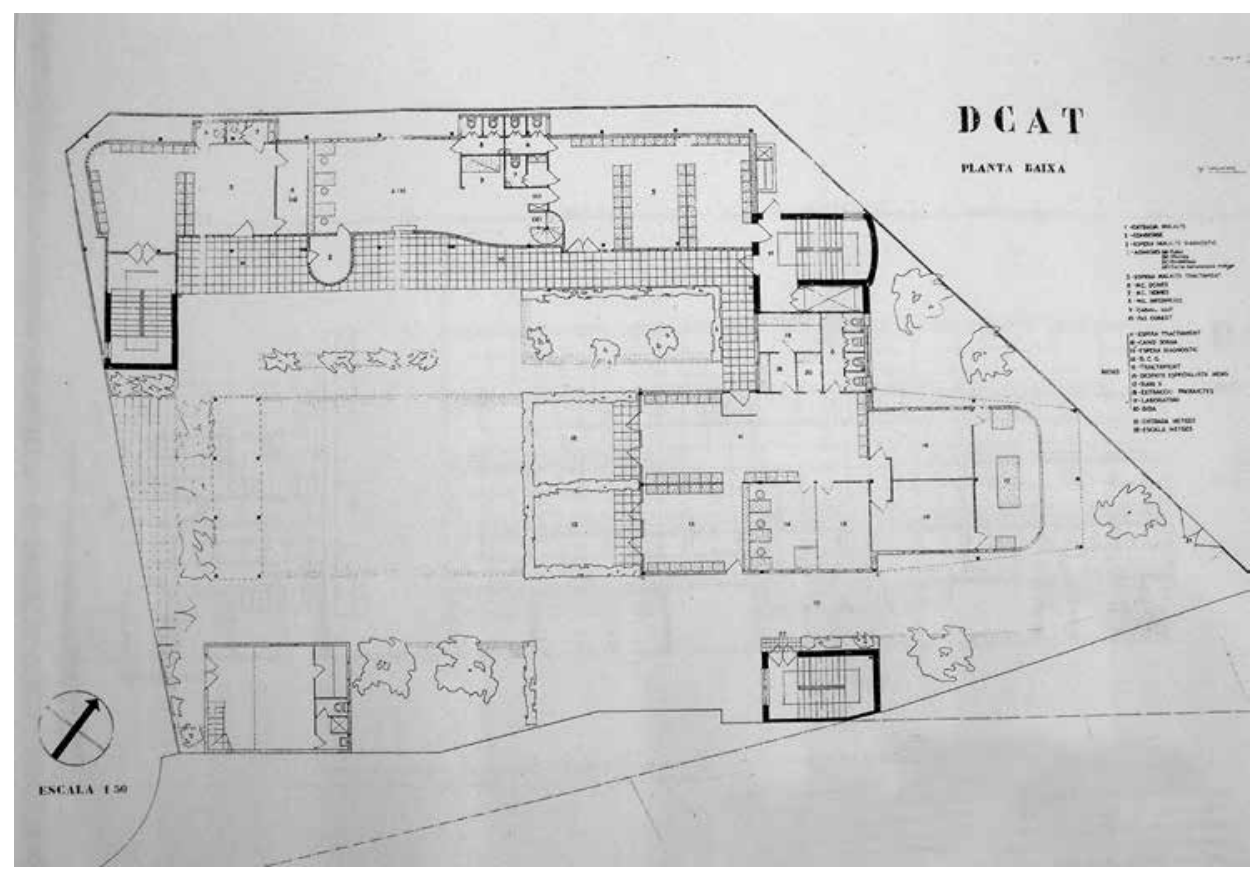

La biblioteca, en el segundo nivel, se asoma también hacia al jardín, protegida en el lado meridional por un muro bajo revocado, de color amarillo ocre, sobre el cual se levanta la casa del guardia. Dos de los tres cuerpos de escaleras están ubicados al extremo de los cuerpos principales y el tercero en su ángulo de encuentro conformando una bisagra entre los dos volúmenes.

\section{Los principios del proyecto}

El Dispensario antituberculoso es un injerto de un edificio Moderno al interior del tejido del antiguo barrio el Raval. ${ }^{19}$

Es un edificio compuesto por dos cuerpos principales dispuestos en forma de "L", uno de los cuales se alinea sobre el carrer Torres i Amat.

El espacio público central a cielo abierto es el resultado de la composición volumétricoarquitectónica y está atravesado por un pasaje urbano que conecta el Carrer de San Bernat con la Plaza Castilla.

En el edificio se funden técnicas y materiales modernos - como por ejemplo el ensamblaje de elementos prefabricados de medida estándar - y técnicas constructivas, materiales y colores propios de la tradición constructiva catalana. ${ }^{20}$
Figura 3. Planta baja. Fuente: Archivo administrativo de Barcelona, suministrada por el autor

9 "A lo largo de la historia tenemos varios ejemplos felices de integración como la construcción del Dispensario Antituberculoso de Barcelona que supo introducir un fragmento moderno en el tejido histórico, haciéndose una excelencia de su contexto". O.Bohigas, Assistiamo ad una preponderanza neoliberale nell'organizzazione della città, una conversación entre el crítico Antonio Pizza y el maestro Oriol Bohigas, en la revista “Área”, No. 90, Milán 2007, pp. 44-53.

20 A propósito de la reinterpretación de los caracteres de la arquitectura tradicional catalana en la Investigación de Sert y Torres se remite al texto de Peter Buchanan: Monumentos a una civitas clásico constructivista, en Barcelona, arquitectura y ciudad, 1980-1992, GG, Barcelona 1990, pp. 25-26. 
Se adopta una estructura modular en acero que ordena la composición interior y la subdivisión de los espacios.

En el cuerpo más largo la estructura es independiente de la piel del edificio; en el cuerpo oriental la presencia del auditorio y de la biblioteca conforma el sistema estructural y arquitectónico. La planta baja está retrasada con respecto al hilo de la fachada y la cubierta es un espacio habitable.

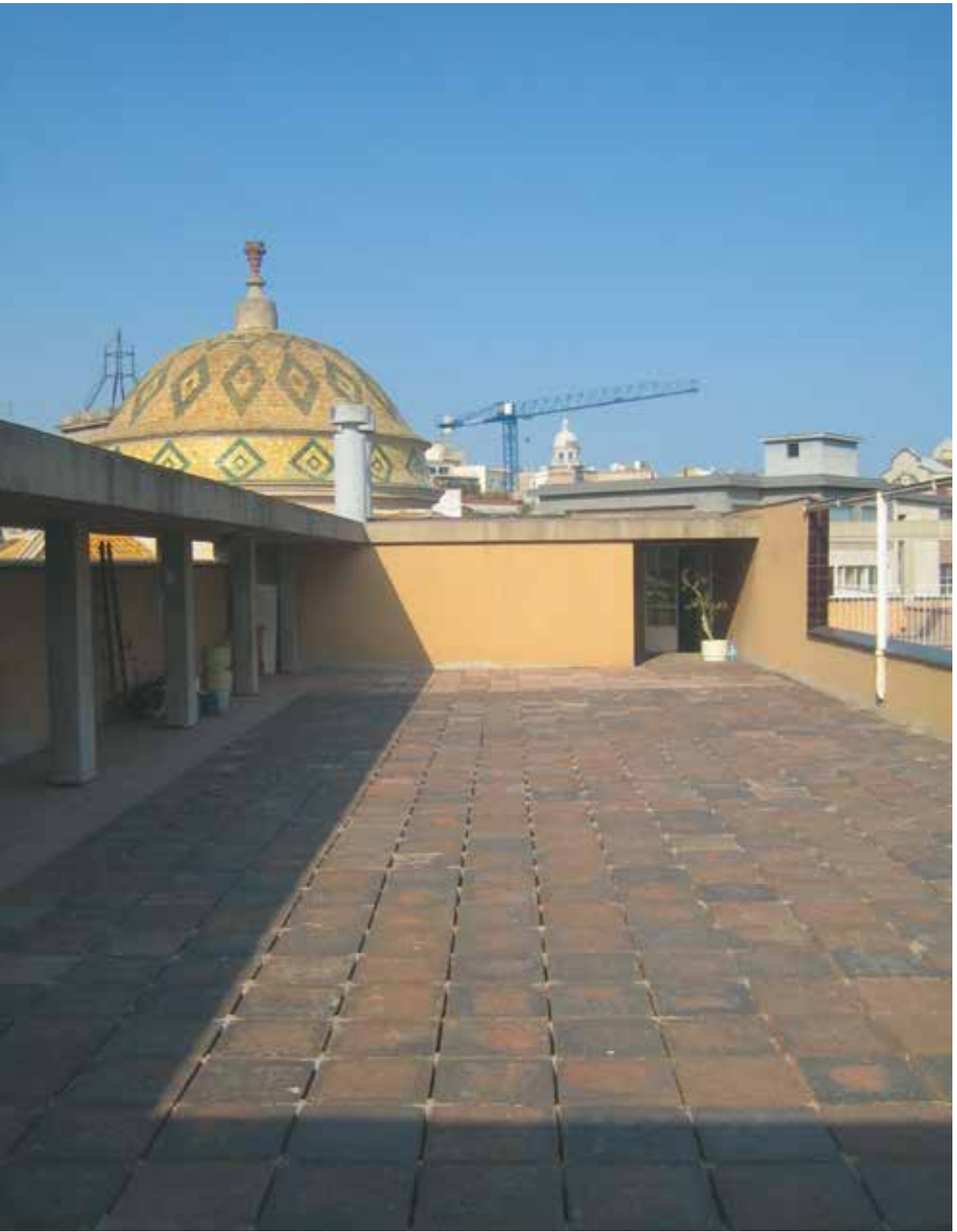

El edificio se proyecta como la sumatoria de dos grandes volúmenes de forma simple: aparece en planta como un cuerpo en " $\mathrm{L}$ " flanqueado en la parte sur por un muro en el cual se apoya el pequeño volumen suspendido de la casa del portero.

La conformación final, en planta, es una "C" que configura el espacio público central a cielo abierto, resultado de la composición volumétrica. Tal espacio está atravesado en dirección este-oeste por un pasaje urbano que conecta el carrer Sant Bernart con la Plaza Castilla. 


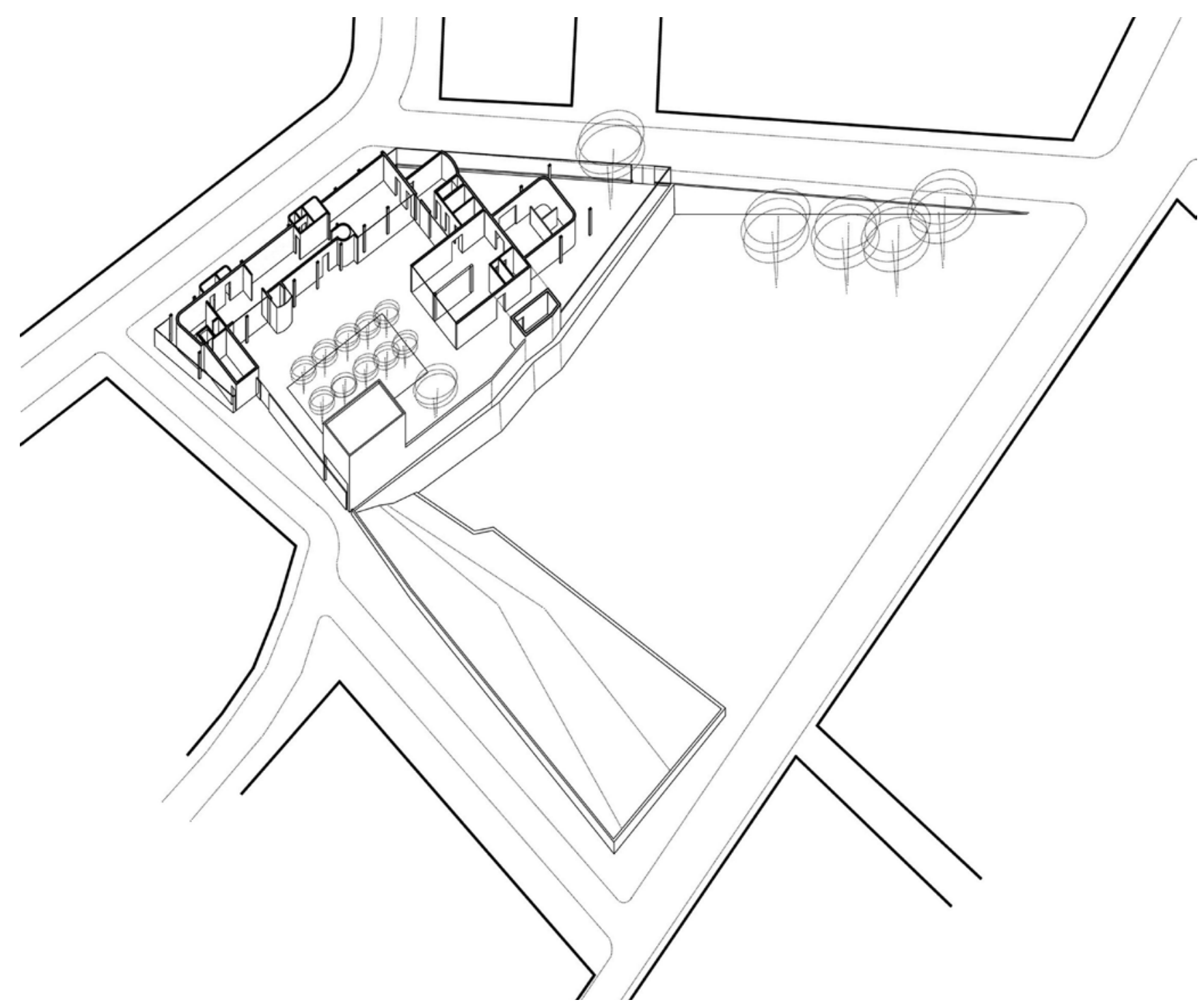

El volumen alargado paralelo al carrer Torres i Amat tiene una estructura en acero retranqueada con respecto al perímetro del edificio. El volumen oriental tiene una estructura del Figura 5. Axonometría del estado actual. Fuente: archivo Luca Bullaro mismo tipo, pero coincide con el perímetro. Los volúmenes de los cuerpos de escaleras son en hormigón armado: dos cierran el edificio en sus extremidades y el tercero actúa como bisagra entre los volúmenes principales.

\section{La reinterpretación de los "5 puntos"}

Sert y Torres Clavé se confrontan con los principios estructurales y formales establecidos por el maestro Le Corbusier ${ }^{21}$, respetándolos en algunos casos, reinterpretándolos en otros e introduciendo algunas características típicas de la arquitectura tradicional catalana, ya sea en la elección de técnicas constructivas utilizadas o en el uso de materiales. En el ámbito de la investigación sobre los principios arquitectónicos del Dispensario, se ha hecho un análisis

2I A propósito de la influencia fundamental del pensamiento y de la obra de Le Corbusier sobre Sert y Torres se remite a las palabras de Oriol Bohigas: "Uno de los aspectos clave del grupo es de ser alumnos de Le Corbusier que trabajan dentro del ámbito cultural de la modernidad en la España republicana. (...) Si se analizan las obras más significativas de los mejores arquitectos del GATCPAC, la referencia a Le Corbusier es inmediata y confesada. (...) por tanto, el GATCPAC es la versión lecorbusierana dentro del Movimiento Moderno de España." "El GATCPAC 75 años después” en AA.W., El GATCPAC y su tiempo, política, cultura y arquitectura en los años treinta. Actas del $\vee$ congreso Fundación DOCOMOMO lbérico, Grup3, Barcelona 2006, p.37 
en relación a los 5 puntos de una nueva arquitectura de Le Corbusier y Pierre Jeanneret, de modo de encontrar analogías y diferencias ${ }^{22}$ :

\section{Pilotis}

La planta baja del volumen largo está retrasada con respecto al hilo de la fachada dejando visible la línea de pilotes en acero, que acompañan al peatón en su recorrido.

La conformación espacial del edificio en la planta baja es tratada de manera diferente con respecto al resto del edificio subraya, de esta manera, el carácter público, señala los accesos y trasmite la sensación de que el edificio está suspendido.

Esto se logra retrasando el hilo de la fachada con respecto al del volumen, y revistiéndolo con un material diferente: azulejos verdes brillantes actúan como metáfora de la naturaleza que entra en la planta baja del edificio - según las reglas de Le Corbusier - en contraposición al revoque opaco del volumen de los niveles superiores.

\section{La Terraza}

La terraza del volumen paralelo al carrer Torres i Amat, cerrada sobre tres lados, se abre hacia el sur y está protegida del sol por un espacio porticado que corre paralelo a la calle y por un sistema de toldos móviles, parecido al que Sert utilizará posteriormente en el Pabellón de la República española. ${ }^{23}$

\section{Planta libre}

En el volumen más largo la planta libre se genera mediante la separación entre la estructura portante y el cerramiento. La planta baja, la segunda y la tercera planta acogen los espacios de acceso, las salas de espera, de reuniones y el archivo. La primera planta estaba subdividida en pequeños ambientes, independientes a la estructura, que albergaban el programa del dispensario como tal.

El cuerpo oriental toma forma a partir de la función de la sala de conferencias que ocupa la segunda y la tercera planta, una estructura de pórticos que coincide con el perímetro externo ${ }^{24}$ y que hospeda en las primeras dos plantas el dispensario destinado a los niños.

\section{Fachada libre}

Las fachadas del edificio son variables en la configuración de las relaciones entre lleno y vacío a causa de la diferente exposición y a de las diferentes exigencias de los espacios interiores. El frente sobre el carrer Torres i Amat se construye con las novedosas ventanas corridas, la fachada hacia al patio es un pan de verre, conformado por superficies transparentes de diferentes texturas y opacidades, que se alterna a membranas llenas. Las superficies vítreas, opacas o transparentes, ocupan la casi totalidad de la fachada.

22 Le Corbusier y P. Jeanneret Cinco puntos para una nueva arquitectura en Roth, Alfred. Dos casas de Le Corbusier y Pierre Jeanneret, COAA, Valencia 1997, pp.35-40.

23 El pórtico de la terraza remite a aquello realizado por Le Corbusier y Jeanneret en una de las dos casas edificadas en el ámbito del Weissenhoff de Stuttgart. Sert reinterpreta el mismo tema en otros proyectos, por ejemplo en la fachada principal de la pequeña escuela en Arenys de Mar, en los alrededores de Barcelona.

24 En la conformación del volumen del Dispensario se puede señalar la influencia de los proyectos de Le Corbusier y Jeanneret para el Palacio de las Naciones de Ginebra y para el edificio Centrosoyus de Moscú. Véase Pizza, Antonio, Dispensario antituberculoso de Barcelona 1933-1937, COAA, Almería 1993. 


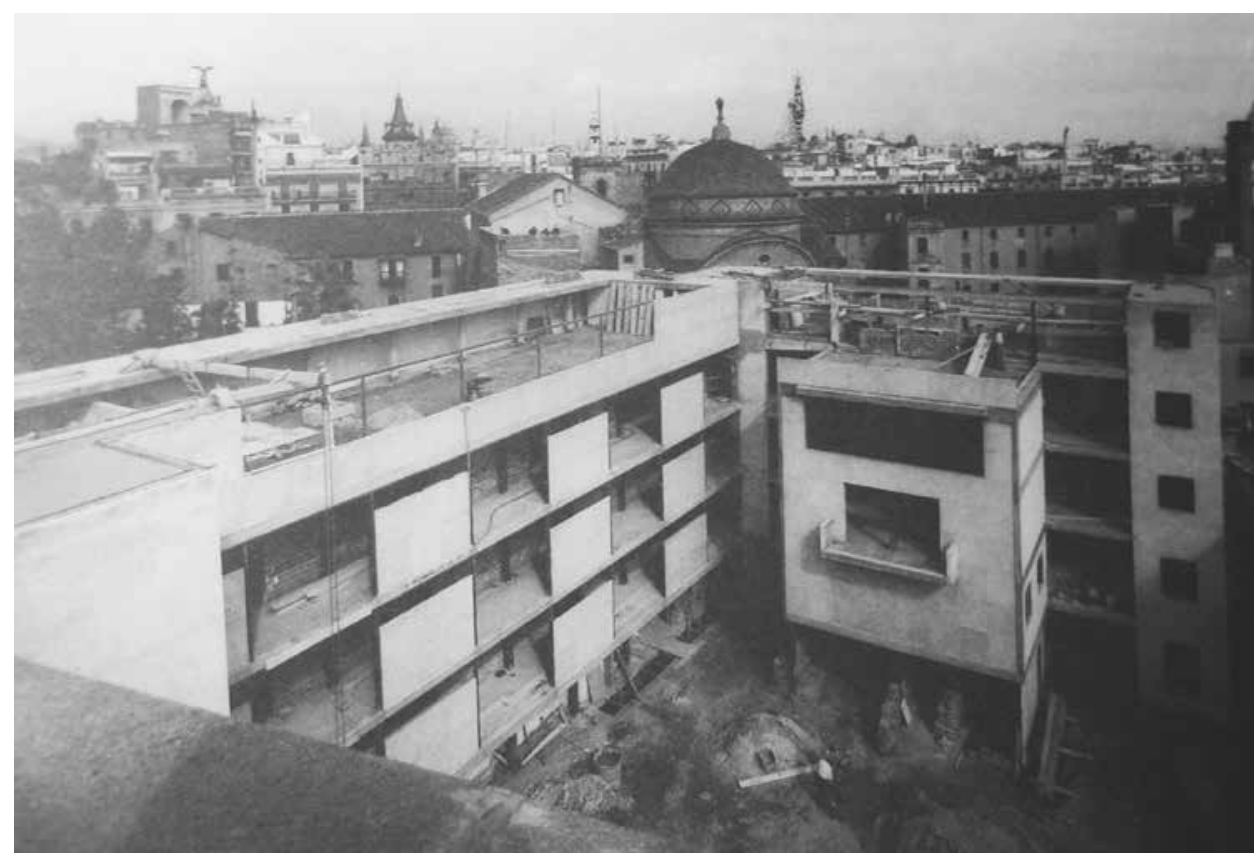

Figura 6. fotografía de la construcción 1934. Fuente: archivo Revista 2C, Barcelona, suministrada por el autor.

El módulo del pan de verre está constituido de dos partes: la porción inferior en elementos cuadrados de vidrio auto portantes y la parte superior de vidrio transparente que se puede abrir para que los pasillos sean ventilados y frescos.

Las ventanas corridas en la fachada que se asoma hacia el carrer Torres i Amat se interrumpen en la parte central del segundo piso, para que se vuelva clara la presencia en el interior de los espacios en doble altura de los archivos. La función de los espacios interiores se explicita entonces en el exterior. En el cuerpo oriental las ventanas se diferencian también según la función originaria de los espacios interiores:

- Cuadradas donde se encuentran las áreas para las consultas médicas y los despachos.

- Rectangulares alargadas, en horizontal - colocadas por debajo del intradós del forjado - en correspondencia de los servicios higiénicos.

- Rectangulares, de grandes dimensiones, para iluminar los espacios en doble altura del salón de actos, de la biblioteca y de las salas de espera en la planta baja.

En los volúmenes de las escaleras se utilizan ventanas rectangulares alargadas, de tipo vertical, que iluminan las paredes curvas de los descansos.

\section{Arquitectura estandarizada}

La planta de los dos cuerpos presenta una organización modular repetitiva - que se explicita a nivel constructivo mediante pilares y vigas metálicas estandarizadas - que ordena los espacios internos y separa los espacios de servicio y los espacios servidos. Los forjados se ensamblan a partir de tradicionales arcos catalanes en ladrillo que unen las viguetas estandarizadas de acero. ${ }^{25}$

25 Para la relación entre modernidad y tradición en la arquitectura de los treinta de Sert y Torres Clavé se remite a Bohigas, Oriol, Arquitectura i urbanisme durant la Repùblica, Tusquets de., Barcelona 1970, pp. 66-70. 
Figura 7. Fotografía aérea del Raval, Barcelona. Fuente: Tomada de google, 200I, suministrada por el autor
Las fachadas se construyen a partir de la repetición de sistemas de elementos prefabricados, sean opacos o transparentes.

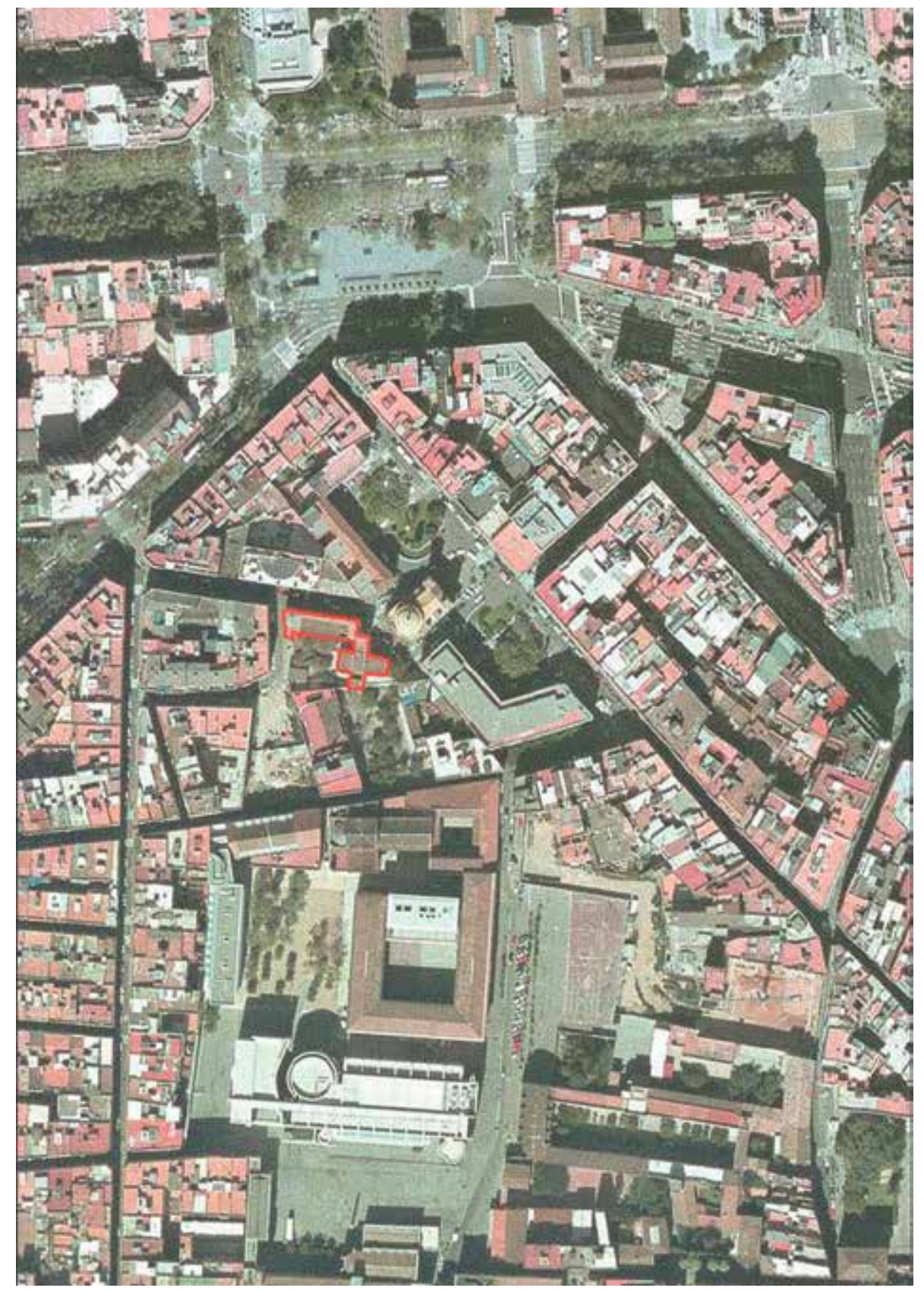

\section{El proyecto de rehabilitación}

El análisis en paralelo de las condiciones actuales de la construcción y del proyecto de los años treinta llevó a señalar que actualmente los principios originales del proyecto del Dispensario se encuentran desvirtuados a causa de las nuevas funciones introducidas, del aislamiento de la construcción con respecto a su entorno (como consecuencia del cierre del pasaje urbano original) y de la negación de la relación de continuidad interior-exterior, seguida a la alteración de los espacios del primer nivel que se asoman al patio (de públicos, a privados). 


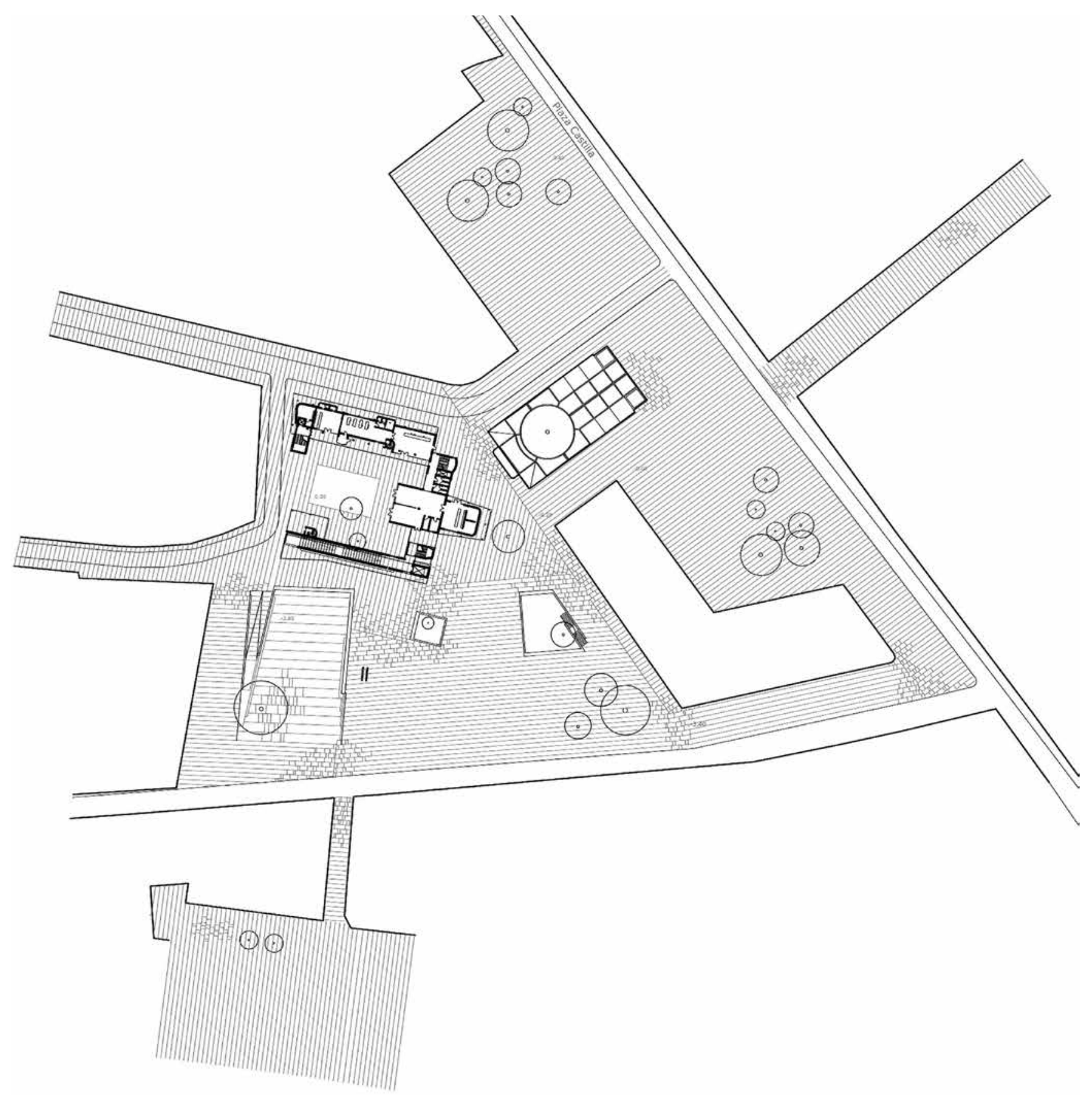

La investigación llevada a cabo sobre el proyecto de restauración se desarrolló en tres líneas paralelas:

I. La reproducción de la espacialidad arquitectónica pensada en los años treinta, con la reconfiguración de los amplios espacios del segundo y tercer piso, hoy sacrificados a causa de las nuevas exigencias del centro sanitario y el rediseño del patio interior según los principios de Sert y Torres Clavé.

2. La introducción de un nuevo uso que haga posible tal reconfiguración aceptando como hipótesis de partida, planeada por la Escuela de Arquitectura de la UPC de Barcelona, el requisito de instaurar, al interior del edificio, un centro de investigación universitaria.
Figura 8. Planta urbana del proyecto. Fuente: Archivo Luca Bullaro, 2011 
3. La reorganización de los espacios del primer nivel, se amplifica la relación interiorexterior, se elimina la cerca que hoy en día encierra los espacios del Dispensario y se conecta con mayor intensidad los ámbitos - que en futuro se imaginan totalmente públicos - entre el edificio y la ciudad.

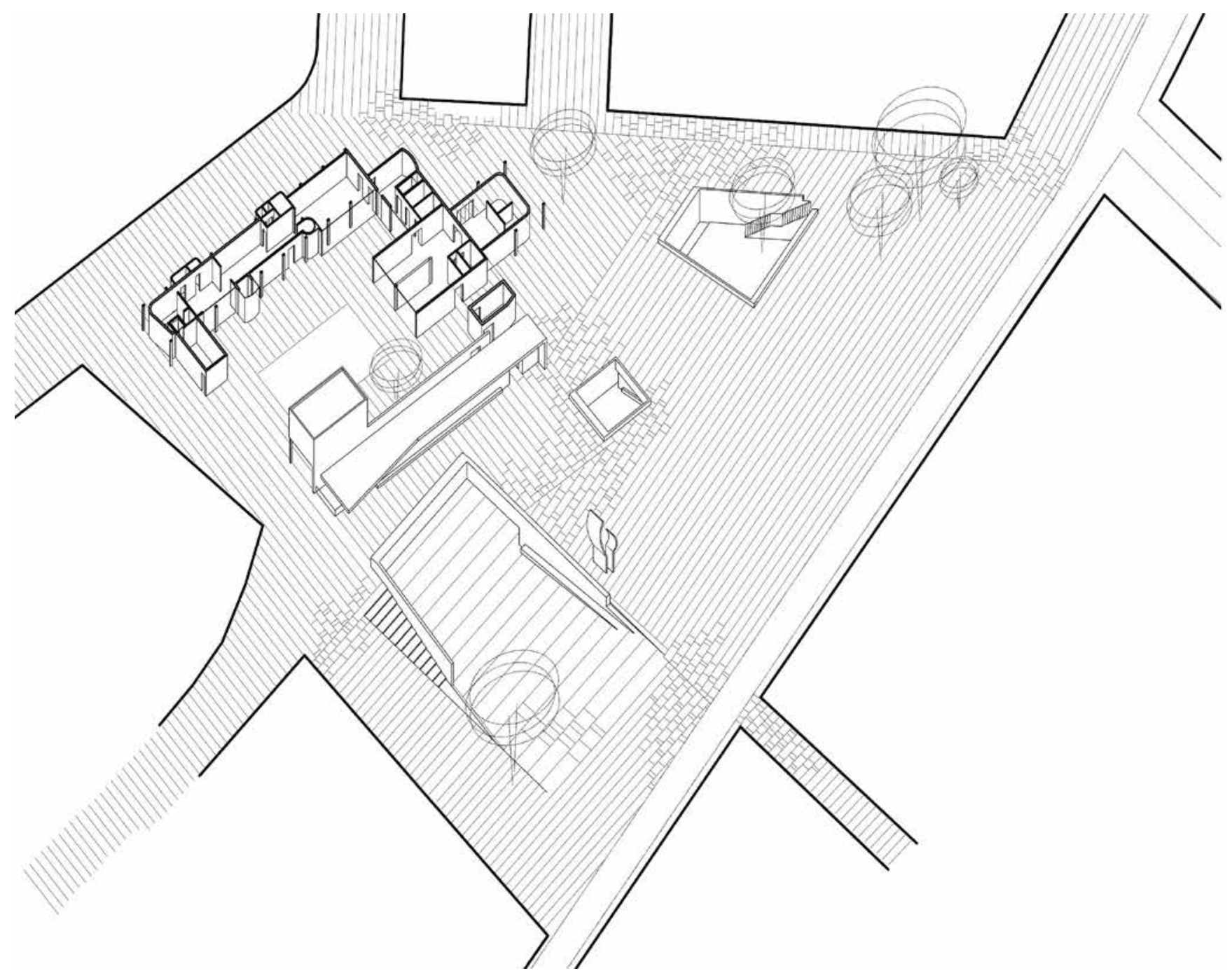

Figura 9. Axonometría del proyecto. Fuente: Archivo Luca Bullaro, 2011
El primero es un proyecto de reconfiguración y recreación de la espacialidad original que tiene en cuenta los principios del proyecto del Moderno y que está asociado con la nueva modalidad de uso.

El segundo de actualización funcional con el fin de facilitar la rehabilitación misma.

El tercero es un propósito que nace de los cambios esenciales que ha sufrido en los últimos años la zona que circunda el edificio: de barrio insano y difícil, el actual Raval ha cambiado su fisionomía transformándose en un sistema integrado de espacios públicos y de servicios colectivos, museos y universidades.

El proyecto de restauración arquitectónica y urbana pretende introducir el edificio en este sistema cultural, expositivo y arquitectónico que en los últimos años se ha vuelto un modelo de referencia mundial para las reflexiones proyectuales en el ámbito de las reconfiguraciones urbanas. 


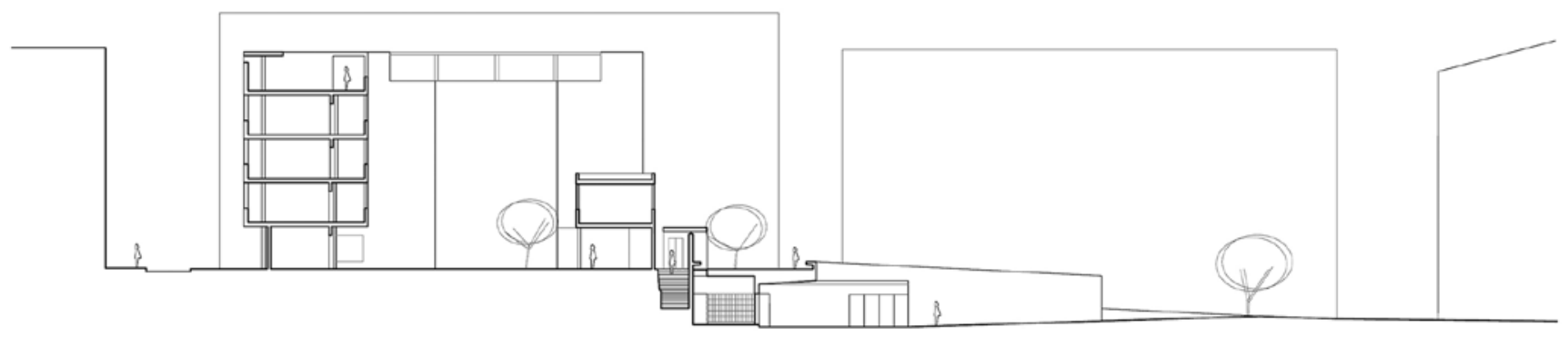

Figura 10. Sección transversal. Archivo Luca Bullaro, 2011

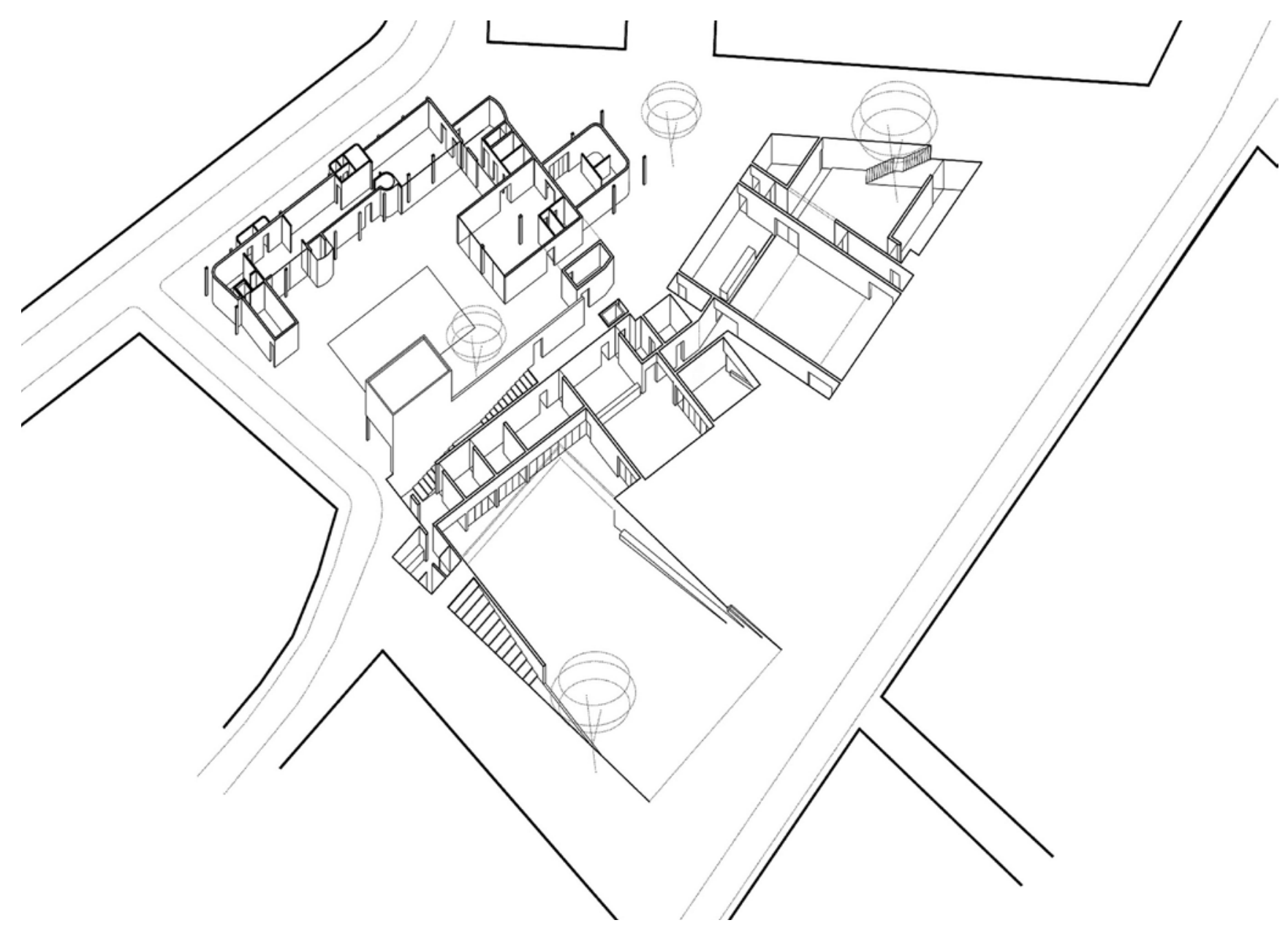




\section{BIBLIOGRAFÍA}

Arquitectura catalana en los años veinte y treinta

BOESIGER, Willy (Ed.). Le Corbusier, Oeuvre Complete, 1910-1969. Basilea: Birkhäuser Verlag, 1995

BOHIGAS, Oriol. Architettura spagnola della Seconda Repubblica. Bari: Laterza, 1978

BOHIGAS, Oriol. Modernidad en la arquitectura de la España republicana. Barcelona: Tusquets Editores, 1998

DE MUGA, Patricia, GARCÍA HINTZE, Laura. Barcelona Arquitectura moderna 19291979, Barcelona: Actar, 2007

DE SOLÀ-MORALES RUBIÓ, Ignasi. Eclecticismo y vanguardia. El caso de la Arquitectura Moderna. Barcelona: Tanais Ediciones, 1980

GAUSA, M., CERVELlÒ, M. Pla, M., Barcelona: A guide to its modern Architecture. Barcelona: Actar, 200I

GIEDION, Sigfried. Escritos escogidos. Murcia: COAA, 1997

GONZÁLEZ, A., LAQUESTA, R. Guia de Arquitectura 1929-2000. Barcelona: GG, 1999

LAHUERTA, Juan José. Le Corbusier e la Spagna. Milano: Electa, 200 I

LANDROVE, S. (al cuidado de) El GATCPAC y su tiempo, política, cultura y arquitectura en los años treinta, Barcelona: Actas del $\mathrm{V}$ congreso DOCOMOMO ibérico, Barcellona, 26-29 ottobre 2005, Grup3, 2006

LE CORBUSIER. Encuentro con la obra de Gaudí. En: AA.W., Gaudí. Barcelona: Ediciones Polígrafa, 1967

LLINÁS CARMONA, Josep. GATCPAC Ciudad del Reposo y Caseta desmontable. 19311935. Madrid: MOPT, 2005

MONTANER, Josep María. Arquitectura Contemporánea a Cataluña. Barcelona: Edicions 62, 2005

MONTEYS, Xavier. (al cuidado de). Le Corbusier i Barcelona. Barcelona: Fund. Caixa de Catalunya, 1988

MONTEYS, Xavier. Le Corbusier, Obras y Proyectos. Barcelona: GG, 2005

PIZZA, Antonio, ROVIRA, J. M. La tradición renovada. Años 30. Barcelona: Actar, 1999

PIZZA, Antonio. Guía de la arquitectura moderna en Barcelona (1928-1936). Barcelona: Ediciones del Serbal, 1996 
PIZZA, Antonio., ROVIRA, J. M. (a cura di) GATCPAC Una nova arquitectura per a una nova ciutat. Barcelona: COAC publicaciones, 2006

ROVIRA, José María. La arquitectura catalana de la modernidad: 1901-1951. Barcelona: ETSAB, 1987

VEGA, C. M. Arquitectura de los años 30 en Barcelona. Barcelona, 2005 La obra de Sert, Torres Clavé y del GATCPAC

AA.W. Arquitectura del Movimiento Moderno. Registro DOCOMOMO Ibérico, 19251968. Barcelona: Actar, 1996

AA.W. J. L. Sert, Arquitectura en Ibiza. Ibiza: COAIB ed., 1983

ACIERNO, V., Architettura in Catalogna. La modernità moderata e il realismo costruttivo, Palermo: lla palma, 2006

BASTLUND, K., SERT, Josep Lluís. Architecture, city planning, urban design. New York: Praeger, 1967

BOHIGAS, Oriol. Arquitectura i urbanisme durant la República. Barcelona: Tusquets Editores, 1970

COSTA, Xavier. Sert, arquitecto en Nueva York, Barcelona: Actar, 1997

FREIXA, Jaume. Josep LI. Sert 1902-1983, Barcelona: GG, 1998

FREIXA, Jaume. Josep Lluis Sert. Barcelona: Santa \& Cole, 2005

JULBE, Félix. Arquitectura en Ibiza, José Luis Sert. Mallorca: COAIB ed., 2002

LAHUERTA, Juan José. Le Corbusier e la Spagna. Milano: Electa, 2001

MACKAY, D., L’arquitectura moderna a Barcelona (I854- 1939). Barcelona: Edición 62, I 985

MANNINO, Edgardo, PARICIO, Ignacio. J. L. Sert: Costrucciòn y arquitectura, Barcelona: GG, 1983

PIZZA, Antonio. J. LI. Sert y el Mediterráneo. Barcelona: Actar, 1997

PIZZA, Antonio., Dispensario Antituberculoso de Barcelona 1933-1937, Almería: Colegio de Arquitectos de Almería ed., 1993

ROVIRA, Josep M. José Luis Sert 1902-1983. Milano: Electa, 2000

ROVIRA, Josep M. Sert 1928-1979. Medio siglo de arquitectura. Obra completa, Barcelona: Actar, 2005 
ROVIRA, Josep M., Urbanización en Punta Martinet, Ibiza, 1966-197I. Almería: Colegio de Arquitectos de Almería ed., 1996

ROVIRA, Josep M., FREIXA, Jaume. Sert: de la ciutat funcional al disseny urbá. Barcelona: UPC ed., 2006

SERT, Josep Lluís Sweeney, J., Antoni Gaudì, , Buenos Aires: Ed.Infinito, 196I

SERT, Josep Lluís,Rogers, E. N., Tyrwitt, J., II cuore della città: per una vita più umana delle comunità. Milano: Hoepli, 1954

SERT, Josep Lluís. Ibiza fuerte y luminosa. Barcelona: Ed. Polígrafa, 1967

SERT, Josep Lluís. Can our cities survive? And ABC of urban problems, their analysis, sobreviure les nostres ciutats?, Generalitat de Catalunya ed., Barcelona 1983) their solutions. Harvard University Press, Cambridge, 1942 (ed. en catalan: Poden)

TORRES, M. (al cuidado). Josep Lluis Sert, Cicle de conferències. Ibiza: COAIB ed., 2007

TORRES, R., Josep Torres Clavé, Santa \& Cole, Barcelona 1994

ZEVI, Bruno. Sert's architecture in the Mirò Foundation, Ed. Polígrafa, Barcelona: Ed. Polígrafa, 1976

\section{Revistas}

BOHIGAS, Oriol. Homenaje al GATCPAC. En: «Cuadernos de Arquitectura y Urbanismo», n. 40, marzo 1960. pp. 43-44

BOHIGAS, Oriol. "Assistiamo ad una preponderanza neoliberale nell'organizzazione della città..." Intervista a cura di Antonio Pizza. En: «Area», n. 90, Milano, gennaio 2007, pp. 44-53.

CAPELLUTO, Martín. La conservación del las obras del GATCPAC y su autenticidad, en «Dc, Revista de crítica arquitectónica», ETSAB-UPC, Barcelona, n. 13-14, octubre 2005. pp. |74-|8|.

COREA, M., Mannino, E., Gallardo-Bravo, F., C.G.M. Arquitectos Asociados. Aprendiendo junto a Josep Lluis Sert, en «Diseño interior», n. 23, marzo 1993. pp. 73-75.

«Dc, Revista de crítica arquitectónica», n. I3-I4, número monográfico sobre el GATCPAC, octubre 2005 
«Dc, Revista de crítica arquitectónica», ETSAB-UPC, Barcelona, n. 9-10, octubre 2003.

FANCELLI, Agustí. Torres Clavé, el agitador del GATPAC. En: «El País», I 2 febrero 2007

FERNÁNDEZ-GALIANO, Luis. Sert o no Sert: el maestro menguante. En: «El País», 30 junio 2001 .

FORT, J. M. El dispensario antitubercoloso de Sert: recuperación de un ejemplo paradigmático de la modernidad catalana: Mario Corea, Edgardo Mannino y Francisco Gallardo. En: «Diseño Interior», n. 23, Barcelona, marzo 1993. pp.62-72.

FRAMPTON, Kenneth. Rehabilitación del Dispensario Central Antituberculoso de Barcelona, M. Corea, F. Gallardo-Bravo, E. Mannino, arquitectos. En: «ON Diseño», n. I6I, marzo 1995. pp. I72-I8I

HERNÁNDEZ MARTÍNEZ, Ascensión. II recupero della memoria culturale: la conservazione dell'architettura del Movimento Moderno nella Penisola lberica, En: «Parametro», n. 266, Milano, octubre 2006, pp. 48-55.

LEROY, A. Luogo del risanamento, Restauro e progetto. En: «Area» n. 16, dicembre 1993. p. 34-4I.

SERT, Josep, LI. Apuntes autobiográficos. En: «Revista del Consejo superior de los Colegios de Arquitectos de España», abril 1983. pp. I3-14

TORRES, R., Dispensario Central Antituberculoso, Ciutat vella, Barcelona, en «Arquitectura» n. 303, marzo 1995, pp. 85-90.

(Red) Tuberculosis clinic, Barcelona. (1934-1938) architects: Josep Lluis Sert, Josep Torres Clave, and Joan Baptista Subirana, of GATCPAC. En: «A\&U» n. 7, julio I 984. pp. 90-97.

(Red) Dispensario central antituberculoso. En: «2C, construcción de la ciudad» n. I5- I6, número monográfico dedicado a la obra de J. Torres Clavé, mayo 1980. pp. 62-67. Disponible en: http://upcommons.upc.edu/revistes/bitstream/2099/5306/6/Article I2.pdf

(Red) El Dispensario antituberculoso de la calle Torres Amat: Arquitectos: J. Luis Sert, J. Torres Clavé, J. B. Subirana. En: «Cuadernos de Arquitectura y Urbanismo», n. 40, marzo 1960. pp. 6-II. Disponible en: http://www.raco.cat/index.php/CuadernosArquitectura/ article/view/ 109500 